\title{
Ketogenic Diet Slows Down Weight Gain in Juvenile Mus musculus with Benzopyrene as Cancer Inducer
}

\author{
Dita Mega Utami ${ }^{1}$, Lilik Herawati ${ }^{2}$, Reny I'tishom ${ }^{3}$, Mohammad Anam Al-Arif ${ }^{4}$, Muhammad \\ Miftahussurur ${ }^{5}$, Purwo Sri Rejeki ${ }^{2}$ \\ ${ }^{1}$ Student, Faculty of Medicine, Universitas Airlangga, Surabaya, Indonesia, ${ }^{2}$ Lecturer, Department of Physiology, \\ Faculty of Medicine, Universitas Airlangga, Surabaya, Indonesia, ${ }^{3}$ Lecturer, Department of Medical Biology, \\ Faculty of Medicine, Universitas Airlangga, Surabaya, Indonesia, ${ }^{4}$ Lecturer, Department of Animal Husbandry, \\ Faculty of Veterinary Medicine, Universitas Airlangga, Surabaya, Indonesia, ${ }^{5}$ Lecturer, Department of Internal \\ Medicine, Dr. Soetomo General Hospital, Surabaya, Indonesia
}

\begin{abstract}
Objective: This study aims to analyze the ketogenic diet that slows down weight gain in juvenile Mus musculus induced with benzopyrene (BZP). Method: Thirty-six female mice (Mus musculus), 6-8 weeks old, weighted 15-25 grams were divided into six groups randomly. K1 (negative control, standard diet) induced with oleum olivarum, while K2 (positive control, standard diet), P1 (ketogenic diet 1), P2 (ketogenic diet 2), P3 (ketogenic diet 3) and P4 (ketogenic diet 4) induced with BZP subcutaneously in the right breast at a dose of $0.3 \mathrm{mg} / 20 \mathrm{gBB} /$ day for 14 days. The ketogenic diet was given for the next 28 days. Data were analyzed using the ANOVA and post hoc LSD test. Results: After 42 days, the ketogenic diet mice experienced slower weight gain $(\mathrm{p}=0.000)$ because BZP induced neurotoxicity and the administration of the ketogenic diet in juvenile mice induced neurohormonal changes. The ketogenic diet increased ketone plasma level $(p=0.000)$ and reduced blood glucose levels $(p=0.002)$ due to nutritional ketosis state. Conclusions: The ketogenic diet with fat:protein ratio 60:30 slows down weight gain, increased ketone levels and decreased blood glucose levels in juvenile mice with BZP as cancer inducer.
\end{abstract}

Keywords: ketogenic diet, weight gain, benzopyrene induced, ketone, blood glucose

\section{Introduction}

The ketogenic diet is a high fat and low carbohydrates diet that has been used for various purposes such as treatment for epilepsy in children and adults, type 2 diabetes mellitus and obesity ${ }^{1,2}$. The ketogenic diet has the side effect of losing weight. However, children with epilepsy who are given the ketogenic diet have gained weight at a slower rate ${ }^{3}$. Benzopyrene (BZP) is a polycyclic aromatic hydrocarbon $(\mathrm{PAH})$ compound that can be found in daily life. Humans can be exposed to BZP in air, water, and food through the skin, ingestion, and residual inhalation. As a food contaminant, BZP

\section{Purwo Sri Rejeki}

Email: purwo-s-r@fk.unair.ac.id; purwo_faal@yahoo.com has been widely known to be a causative agent for some cancer. BZP metabolized in the liver by the CYP1A1 enzyme and produce carcinogenic metabolites that cause mutation in cells. Several studies in mice showed that BZP induction can cause tumors such as breast, skin, lung and liver cancer. In humans, exposure to BZP in the work environment is associated with the worker's cancer incidence, for example, coal workers, cigarette smokers, also paving and tile makers ${ }^{4}$.

Since 1983, Rudolf Virchow has suggested the role of inflammation in carcinogenesis after discovering numerous inflammatory cells invaders surrounding tumor cells. Inflammation plays a role in two stages of carcinogenesis, namely initiation and progression. A clear association between chronic inflammation and cancer can be found in Hepatitis B virus infections 
and hepatocellular carcinoma ${ }^{5}$. The inflammatory and glycemic responses are interdependent. A sustained inflammatory response will increase glycolysis, followed by hypoglycemia as a follow-up process ${ }^{6}$. This is in line with Warburg postulate that cancer cells metabolized glucose to fulfil their energy needs ${ }^{7}$.

Proinflammatory cytokines have an important role in insulin resistance, which is a key factor of metabolic changes in cancer. This changes will increase energy expenditure, systemic stress and normal cell function ${ }^{8}$. Unlike normal cells, cancer cells need more nutrients from their host to continue growing. These causes weight loss in cancer model animals ${ }^{9}$. Weight loss is one of the consensus criteria for cancer anorexia-cachexia syndrome (CACS). The ideal drug in the treatment of CACS should increase appetite, produce weight gain, improve quality of life, do not interfere with cancer treatment, and have an adequate tolerance profile ${ }^{10}$. Administration of the ketogenic diet is known to cause slower weight gain in juvenile wild type mice ${ }^{11}$.

The ketogenic diet is expected to reduce blood glucose levels and the inflammatory process due to changes in the body's main energy source to ketones. Thus, it is expected there will be an improvement in the cancer conditions. This study aims to analyze the ketogenic diet that slows down weight gain in juvenile Mus musculus with BZP as cancer inducer.

\section{Materials and Methods}

\section{Experimental Animal:}

Thirty-six female mice (Mus musculus) aged 6-8 weeks old and weighted $20 \pm 5$ grams were obtained from the Pusat Veteriner Farma Surabaya. Mice cages measuring $30 \times 45 \times 20 \mathrm{~cm}$, made of plastic covered with gauze equipped with a place to eat and drink bottles, each cage filled with one group of six mice. Mice were placed at room temperature and the lighting was regulated by a light-dark cycle 12 hours respectively. The feeding was done at 09.00-10.00 a.m. ad libitum.

\section{Chemicals:}

The benzopyrene (BZP) was obtained from SigmaAldrich. BZP solution is prepared by dissolving BZP in oleum olivarum in the ratio of $100 \mathrm{mg}$ of BZP to $100 \mathrm{~mL}$ of oleum olivarum ${ }^{25}$.

\section{Experimental design:}

Thirty-six female mice were divided into six groups randomly. K1 induced with oleum olivarum, while K2, P1, P2, P3 and P4 induced with BZP subcutaneously in the right breast area as much as $0.3 \mathrm{mg} / 20 \mathrm{gBB}$ /day for 14 days. BZP was used to induce cancer. During 14 days (day 1-14) of induction, all groups were given a standard diet $(60.3 \%$ carbohydrate, $17 \%$ protein, and $9.3 \%$ fat). Then, in the next 28 days (day 15-42) dieting namely K1(negative control, standard diet), K2(positive control, standard diet), P1(ketogenic diet with a ratio of 30\% fat, $0 \%$ carbohydrate, $60 \%$ protein, and $10 \%$ fiber), $\mathrm{P} 2(45 \%$ fat, $0 \%$ carbohydrate, $45 \%$ protein, and $10 \%$ fiber), $\mathrm{P} 3(60 \%$ fat, $0 \%$ carbohydrate, $30 \%$ protein, and $10 \%$ fiber) and $\mathrm{P} 4(75 \%$ fat, $0 \%$ carbohydrate, $15 \%$ protein, and $10 \%$ fiber) were given.

\section{Data collection:}

Bodyweight was measured every two weeks using an HL-3650 heles digital scale (0-5 kg scale). Measurement of blood glucose levels using the Autocheck MultiMonitoring System was done every two weeks and carried out 24 hours after the last ketogenic diet was given. Measurement of ketone levels using Abbott Freestyle Optium Neo Blood Glucose and Ketones was done every two weeks and carried out 24 hours after the last ketogenic diet was given.

\section{Statistical Analysis}

The statistical analysis was performed using SPSS software. The normality test used the Shapiro-Wilk test followed by the homogeneity Levene test, and ANOVA test continued with post hoc LSD test. All data displayed with mean \pm SD and used a significant level of $\mathrm{p}<0.05$.

\section{Results}

The results of data analysis on the delta mean of final and initial bodyweight can be seen in Table 1 . 
Table 1: Delta mean of final and initial bodyweight

\begin{tabular}{|c|c|c|c|c|}
\hline \multirow{2}{*}{ Group } & \multicolumn{3}{|c|}{ Bodyweight (gram) } & \multirow{2}{*}{$\begin{array}{c}\text { ANOVA } \Delta \\
\text { (p-value) }\end{array}$} \\
\hline & Initial & Final & $\Delta$ & \\
\hline K1 & $19.33 \pm 1.21$ & $30.00 \pm 2.61$ & $10.67 \pm 1.75 a$ & \multirow{6}{*}{$0.038 *$} \\
\hline $\mathrm{K} 2$ & $19.83 \pm 3.97$ & $26.33 \pm 3.72$ & $6.50 \pm 2.43 b$ & \\
\hline $\mathrm{P} 1$ & $19.33 \pm 1.86$ & $24.00 \pm 4.34$ & $4.50 \pm 4.04 \mathrm{~b}$ & \\
\hline $\mathrm{P} 2$ & $18.33 \pm 1.63$ & $23.00 \pm 4.20$ & $4.67 \pm 4.68 b$ & \\
\hline P3 & $18.83 \pm 0.75$ & $26.67 \pm 1.21$ & $7.83 \pm 0.75 a$ & \\
\hline $\mathrm{P} 4$ & $19.17 \pm 3.55$ & $27.00 \pm 3.95$ & $7.83 \pm 4.83 \mathrm{a}$ & \\
\hline
\end{tabular}

Note: different superscript shows significant differences $(p<0.05)$

Based on table 1, the mean delta bodyweight of mice at $\mathrm{K} 1$ is higher than $\mathrm{K} 2, \mathrm{P} 1, \mathrm{P} 2, \mathrm{P} 3$ and P4 ( $\mathrm{p}=0.038$ ).

The results of the analysis of the average ketone levels post ketogenic diet can be seen in Table 2.

Table 2: Average ketone levels

\begin{tabular}{|c|r|c|}
\hline Group & Ketone Levels (mmol/L) & ANOVA $\Delta$ (p-value) \\
\hline K1 & $0.45 \pm 0.19 \mathrm{a}$ & \multirow{2}{*}{$0.000^{*}$} \\
\hline K2 & $0.42 \pm 0.12 \mathrm{a}$ & \\
\hline P1 & $0.67 \pm 0.16 \mathrm{a}$ & \\
\hline P2 & $0.75 \pm 0.24 \mathrm{~b}$ & \\
\hline P3 & $1.55 \pm 0.39 \mathrm{~b}$ & \\
\hline P4 & $1.20 \pm 0.30 \mathrm{~b}$ & \\
\hline
\end{tabular}

Note: different superscript shows significant differences $(\mathrm{p}<0.05)$

Based on table 2, the average ketone levels in $\mathrm{P} 3$ were higher than $\mathrm{K} 1, \mathrm{~K} 2, \mathrm{P} 1, \mathrm{P} 2$, and $\mathrm{P} 4$ ( $\mathrm{p}=0.000)$.

The results of the analysis on the mean delta of blood glucose levels post BZP induction and initial blood glucose levels can be seen in Table 3 . 
Table 3: Mean delta of glucose levels post BZP induction and initial blood glucose levels

\begin{tabular}{|c|c|c|c|c|}
\hline \multirow{2}{*}{ Group } & \multicolumn{3}{|c|}{ Blood Glucose Levels (mg/dL) } & \multirow{2}{*}{$\begin{array}{c}\text { ANOVA } \Delta \\
\text { (p-value) }\end{array}$} \\
\cline { 2 - 4 } & Initial & Post BZP Induction & $\Delta$ & \multirow{2}{*}{$* 0.000^{*}$} \\
\hline K1 & $102.00+14.63$ & $60.33+3.72$ & $-41.67+12.32 \mathrm{a}$ & \\
\hline K2 & $98.33+14.47$ & $49.67+6.06$ & $-48.67+14.53 \mathrm{a}$ & \\
\hline P1 & $71.50+28.22$ & $59.50+7.56$ & $-12.00+21.25 \mathrm{bc}$ & \multirow{2}{*}{$-4.67+9.91 \mathrm{~b}$} \\
\hline P3 & $71.17+10.23$ & $66.50+7.23$ & $-1.50+2.26 \mathrm{~b}$ & \\
\hline P4 & $55.50+4.04$ & $54.00+5.14$ & $-52.00+23.53 \mathrm{ac}$ & \\
\hline
\end{tabular}

Note: different superscript shows significant differences $(\mathrm{p}<0.05)$

Based on table 3, the mean blood glucose delta of mice post BZP induction and initial blood glucose at P3 was higher than $\mathrm{K} 1, \mathrm{~K} 2, \mathrm{P} 1, \mathrm{P} 2$, and $\mathrm{P} 4(\mathrm{p}=0.000)$.

The results of the analysis on the mean delta of final and initial blood glucose levels can be seen in Table 4 .

Table 4: Mean delta of final and initial blood glucose levels

\begin{tabular}{|c|c|c|c|c|}
\hline \multirow{2}{*}{ Group } & \multicolumn{2}{|c|}{ Blood Glucose Levels (mg/dL) } & \multirow{2}{*}{$\begin{array}{c}\text { ANOVA } \Delta \\
\text { (p-value) }\end{array}$} \\
\cline { 2 - 4 } & $\begin{array}{c}\text { Two weeks post ketogenic diet } \\
\text { feeding }\end{array}$ & Final & $\Delta$ (final-initial) & \multirow{2}{*}{$0.002 *$} \\
\hline K1 & $129.17+11.99$ & $123.00+13.885$ & $21.00+12.52 \mathrm{a}$ & \multirow{2}{*}{$29.00+9.27 \mathrm{ab}$} \\
\hline K2 & $123.83+16.06$ & $127.33+7.528$ & $15.50+38.28 \mathrm{a}$ \\
\hline P1 & $116.67+12.40$ & $87.00+12.665$ & $18.80+21.90 \mathrm{a}$ & \\
\hline P2 & $116.00+29.04$ & $90.00+16.420$ & $48.67+16.08 \mathrm{~b}$ \\
\hline P4 & $109.17+9.04$ & $104.17+19.438$ & $-15.17+27.80 \mathrm{c}$ \\
\hline
\end{tabular}

Note: different superscript shows significant differences $(p<0.05)$

Based on table 4, the mean delta of mice blood glucose levels at P3 was higher than K1, K2, P1, P2, and P4 $(p=0.002)$. 


\section{Discussion}

The ketogenic diet has been known to cause slower weight gain in both mice and rats ${ }^{11,12,13}$. The present study showed the mean of delta bodyweight of mice at $\mathrm{P} 3$ was lower than those in the K1, K2, P1, P2, and P4 $(\mathrm{p}<0.05)$. This is in line with the study by Sussman et al. which stated that administration of a ketogenic diet with a ratio of $67.4 \%$ fat, $0.6 \%$ carbohydrate, and $15.3 \%$ protein $\mathrm{wt} / \mathrm{wt}$ for 30 days in 6-weeks-old female mice significantly lead to a slower weight gain compared to the control ${ }^{14}$. The ketogenic diet change energy homeostasis, thus children who are given the ketogenic diet experienced slower growth than those on the regular diet. Administration of the ketogenic diet changes the calorie content and lead to several neurohormones changes, such as insulin and leptin which play a role in energy homeostasis regulation. The metabolic changes due to the ketogenic diet cause peripheral neurohormones levels to change ${ }^{3,15}$. The ketogenic diet administered for 4-6 weeks lead to visceral fat accumulation and increased both adiponectin expression and plasma leptin levels. This increased induce slower weight gain in mice because both hormones have an anorexigenic effect. In addition, high fats composition in the ketogenic diet provide a longer satiety effect and indirectly reduce calorie intake $^{13,16}$.

The K2 group experienced the lowest weight gain because it was induced by BZP without a ketogenic diet feeding. BZP induction causes neurotoxicity and inhibition of acetylcholinesterase and cholinesterase (ChE) which has a severe impact on the determinants of survival and performance functions, such as feeding and surviving toxic exposure ${ }^{17}$. The ketogenic diet exerts a neuroprotective effect that reduces injury to cells and modifies inflammation in the brain due to BZP exposure $^{18}$. Increased expression of adiponectin also weakens the inflammatory response by decreasing the pro-inflammatory cytokines secretion ${ }^{16}$.

The ketogenic diet contains high fat and limits consumption of carbohydrates will cause a nutritional ketosis ${ }^{19}$. The average ketone levels in the P3 were the highest $(\mathrm{p}<0.05)$, which is in line with the study by Greene et al. that a 3-months ketogenic diet with $69.1 \%$ fat, $22.9 \%$ protein, and $8.1 \%$ carbohydrates significantly increased fasting ketone levels compared to control $^{20}$.
Increased ketone levels in the P3 was happened due to the replacement of the main energy sources by fat. When the carbohydrate intake fewer than $20 \mathrm{~g}$ /day for 3-4 days, the oxidation of fat through the Krebs cycle is stopped and ketogenesis will occur to form ketone bodies as a substitute energy source for the brain. Ketone bodies can be used as an energy source when the concentration in the blood reaches $4 \mathrm{mmol} / \mathrm{L}$ (equivalent to glucose concentration). In contrast to ketoacidosis, nutritional ketosis does not cause changes in blood $\mathrm{pH}^{19,21}$.

The present study showed the mean glucose levels in the standard diet groups (K1 and K2) were greater than the ketogenic diet groups. This is in line with the study by Ding et al. that mice in the control group have significantly higher glucose levels $(7.0 \mathrm{mmol} / \mathrm{L})$ than ketogenic diet group with fat-carbohydrate:protein ratio 3.1:1 $(6.0 \mathrm{mmol} / \mathrm{L})^{12}$. The ketogenic diet replaced the energy source for the brain into ketone bodies and causes blood glucose levels to remain low ${ }^{19}$. In contrast to the present study, Cooper et al. found that mice who got ketogenic diet, high-fat diet, and high-fat diet plus exercise for 12 weeks experienced moderate increases in blood glucose compared to control group because the ketogenic diet slows down weight gain and did not cause hyperinsulinemia ${ }^{22}$.

The induction of BZP triggers an inflammatory response in mice and increases the use of glucose which results in a hypoglycemic state as a follow-up process ${ }^{6}$. The decreased glucose levels in the K2, P1, P2, P3, and P4 after BZP induction was caused by an inflammatory reaction. Inflammation triggers a glucostatic state where hyperinsulinemia occurs due to a rapid increase in glucose levels, followed by a more rapid decrease ${ }^{23}$. Hypoglycemic conditions trigger upregulation of glucose transporter 3 (GLUT3) on the plasma membrane of monocytes, which is an autoregulation mechanism to protect leukocytes from the detrimental effects of low glucose levels ${ }^{24}$.

The present study showed that mice in the $\mathrm{K} 2$, which induced with BZP and given a standard diet, had the highest final glucose levels. This is caused by persistent inflammation due to BZP induction. Induction of BZP at a dose of $0.3 \mathrm{mg} / 20 \mathrm{gBW} /$ day for 14 days cause changes in the breast cells leading to malignant tumors ${ }^{25}$. The inflammatory condition can be exacerbated by blood 
glucose increased. High blood glucose levels lead to lowgrade inflammation, insulin resistance, and increased inflammatory markers ${ }^{26}$. Medroxyprogesterone (MPA) treatment in cancer patients decreased IL-1, IL-6, and TNF- $\alpha$ serum levels and increased appetite with bodyweight stabilization ${ }^{27}$. The ketogenic diet has similar anti-inflammatory effects by creating a relatively lower blood glucose level and decreasing TNF- $\alpha$, IL-1, and IL-6 secretion ${ }^{16}$.

\section{Conclusion}

The findings suggest that ketogenic diet with fat:protein ratio 60:30 can slows down weight gain in juvenile Mus musculus induced with BZP might be due to neurohormonal changes also its neuroprotective and anti-inflammatory effects. The ketogenic diet increased mice ketone levels and decreased glucose levels due to nutritional ketosis.

Conflict of Interest: The authors declare they have no competing interests.

Ethical Clearance: All research procedures were approved by The Airlangga University Faculty of Veterinary Medicine Research Ethics Commission No. 2.KE142.07.2019.

Source of Funding: No financial support was provided for this project.

Acknowledgements: The authors acknowledge the contribution of Widjiati who helped provide the laboratory and assistants for this study.

\section{References}

1. Williams TJ, Cervenka MC. Clinical neurophysiology practice the role for ketogenic diets in epilepsy and status epilepticus in adults. Clinical Neurophysiology Practice. 2017;2:154160.

2. Saslow LR, Mason AE, Kim S, et al. An online intervention comparing a very low-carbohydrate ketogenic diet and lifestyle recommendations versus a plate method diet in overweight individuals with type 2 diabetes: a randomized controlled trial. Journal of Medical Internet Research. 2017;19(2):e36.

3. Thio LL. Hypothalamic hormones and metabolism. Epilepsy Research. 2013;100(3):245-251.
4. IARC Working Group on the Evaluation of Carcinogenic Risks to Humans. Chemical agents and related occupations. Vol. 100F. International Agency for Research on Cancer; 2012. 111-144p.

5. Haryono SJ, Anwar SL, Salim A. Dasar-dasar biologi molekuler kanker bagi praktis klinis. UGM PRESS; 2018, 332p.

6. Nandivada P, Fell GL, Pan AH, et al. Eucaloric ketogenic diet reduces hypoglycemia and inflammation in mice with endotoxemia. Lipids. 2016;51(6):703-714.

7. Morscher RJ, Aminzadeh-gohari S, Feichtinger G, et al. Inhibition of neuroblastoma tumor growth by ketogenic diet and/or calorie restriction in a CD1Nu mouse model. PLoS One. 2015;1-19p.

8. Das SK, Patel B, Patri M. Neurotoxic effect of benzo[a]pyrene and its possible association with 6-hydroxydopamine induced neurobehavioral changes during early adolescence period in rats. Journal of Toxicology, 2016;2016:8606410.

9. Cree IA. Cancer biology. Methods in Molecular Biology (Cliffton, NJ). 2011;731:1-11p.

10. Tuca A, Jimenez-fonseca P, Gascón P. Clinical evaluation and optimal management of cancer cachexia. Critical Reviews in Oncology/ Hematology. 2013;88(3):625-636p.

11. Ruskin DN, Ross JL, Kawamura M, et al. A ketogenic diet delays weight loss and does not impair working memory or motor function in the R6/2 1J mouse model of Huntington's disease. Physiology and Behavior. 2011;103(5):501-507.

12. Ding $\mathrm{J}, \mathrm{Xu} \mathrm{X}, \mathrm{Wu} \mathrm{X}$, et al. Bone loss and biomechanical reduction of appendicular and axial bones under ketogenic diet in rats. Experimental and therapeutic medicine. 2019;2503-2510p.

13. Ellenbroek JH, Dijck LV, Töns HA, et al. Longterm ketogenic diet causes glucose intolerance and reduced $\beta$ - and $\alpha$-cell mass but no weight loss in mice. American Journal of Physiology. Endocrinology and Metabolism, 2014;306:552$558 \mathrm{p}$.

14. Sussman D, Eede MV, Wong MD, et al. Effects of a ketogenic diet during pregnancy on embryonic growth in the mouse. BMC Pregnancy Childbirth. 2013;13:109-19.

15. Weijenberg A, Rijn MV, Brouwer OF. Ketogenic diet in refractory childhood epilepsy: starting with a liquid formulation in an outpatient setting. Child 
Neurology Open. 2018;5:1-7.

16. Rhyu H, Cho S. The effect of weight loss by ketogenic diet on the body composition, performance-related physical fitness factors and cytokines of Taekwondo athletes. Journal of Exercise Rehabilitation. 2014;10(5):326-331.

17. Gao M, Li Y, Sun Y, et al. Benzo[a]pyrene exposure increases toxic biomarkers and morphological disorders in mouse cervix. Basic Clinical Pharmacology and Toxicology. 2011;109:398406.

18. Dupuis N, Curatolo N, Benoist J, et al. Ketogenic diet exhibits anti-inflammatory properties. Epilepsia. 2015;56(7):95-8.

19. Masood W, Annamaraju P, Uppaluri KR. Ketogenic Diet. StatPearls. 2020.

20. Greene DA, Varley BJ, Hartwig TB, et al. A low-carbohydrate ketogenic diet reduces body mass without compromising performance in powerlifting and Olympic weightlifting athletes. Journal of Strength and Conditioning Research. 2018;32(12):3373-82.

21. Paoli A. Ketogenic diet for obesity: friend or foe? International Journal of Environmental Research and Public Health. 2014;11(2):2092-2107.
22. Cooper MA, Menta BW, Peres-Sanchez C, et al. A ketogenic diet reduces metabolic syndrome-induced allodynia and promotes peripheral nerve growth in mice. Experimental Neurology. 2018;306:149-57.

23. Sariningrat NLPAP, Rejeki PS, Irwadi I. Effect of dietary energy density on increasing blood glucose pattern and hunger-satiety sensation. Indian Journal of Forensic Medicine and Toxicology. 2020;14(2):2374-2378.

24. Piarulli F, Sartore G, Sechi A, et al. Low glucose concentrations induce a similar inflammatory response in monocytes from type 2 diabetic patients and healthy subjects. Oxidative Medicine and Cellular Longevity. 2017;10(6):1-6.

25. Nansi EM, Durry MF, Kairupan C. Gambaran histopatologik payudara mencit (Mus musculus) yang diinduksi benzo $(\alpha)$ pyren dan diberikan ekstrak kunyit (Curcuma longa L.). Jurnal e-Biomedik. 2015;3(1):510-5.

26. Ari C, Murdun C, Koutnik AP, et al. Exogenous ketones lower blood glucose level in rested and exercised rodent models. Nutrients. 2019;11(2330):20.

27. Aoyagi T, Terracina KP, Raza A, et al. Cancer cachexia, mechanism and treatment. World Journal of Gastrointestinal Oncology. 2015;7(4):17-29. 